\title{
G semem \\ What Determinants Are Needed to Hookah Smoking Control: a Qualitative Study
}

\section{Sakineh Dadipoor}

Tobacco and Health research center, Hormozgan university of medical sciences , Bandar abbas , Iran

\section{Ali Heyrani}

Social Determinants in Health Promotion Research Center, Hormozgan Health Institute, Hormozgan University of Medical Sciences, Bandar Abbas, Iran

\section{Mehdi mirzaei-Alavijeh}

Social Development and Health Promotion Research Center, Health institute, Kermanshah University of Medical Sciences, Kermanshah, Iran

\section{Teamur Aghamolaei ( $\nabla$ teaghamolaei@gmail.com )}

Cardiovascular Research Center, Hormozgan University of Medical Sciences, Bandar Abbas, Iran

\section{Mohtasham Ghaffari}

Environmental and Occupational Hazards Control Research Center, School of Public Health, Shahid Beheshti University of Medical Sciences, Tehran, Iran

\section{Amin Ghanbarnezhad}

Tobacco and Health research center, Hormozgan university of medical sciences , Bandar abbas , Iran

\section{Research Article}

Keywords: Waterpipe, shisha smoking, hookah pipe, women, nicotine dependence, smoking cessation, Hormozgan

Posted Date: April 26th, 2021

DOI: https://doi.org/10.21203/rs.3.rs-418050/v1

License: (9) This work is licensed under a Creative Commons Attribution 4.0 International License. Read Full License 


\section{Abstract}

Background: There is evidence that HS is correlated with severe diseases. The present research aims to explore the determinants of hookah smoking (HS) control in Bandar Abbas city in the south of Iran.

Method: This study is the first qualitative conventional content analysis of the determinants of hookah smoking (HS) control between 2018 and 2019. The participants were 62 in number (21 women with a history of failed cessation, 20 with successful cessation and 21 experts in tobacco consumption control) were selected purposively to take part in a semi-structured interview. An interview guide was followed and the interviews continued until data saturation. The interviews were audio-recorded and then transcribed verbatim. MAXQDA 10.0 was used for data analysis.

Results: The participants. Overall, 5 main themes were extracted: Employing trusted influentials to address HS, Controlling HS by alternative services, Changing beliefs and attitudes toward HS, Executing administrative and regulatory measures, Facilitating HS cessation.

Conclusion: The results revealed that the key determinants of controlling hookah smoking are wide and varied. They are also multi-dimensional and include different environmental, social and political factors. Controlling hookah smoking can be only effective when all individual, inter-individual, social, political and organizational determinants are considered.

\section{Background}

The majority of hookah smokers (HSs) believe that hookah is less detrimental than cigarettes, while there is evidence that HS is correlated with severe diseases [1]. Its adverse effects are worse than cigarette smoking too $[2,3]$.

Flavored tobacco and the absence of regulatory policies have led to HS increase at a global scale [4]. According to recent estimates of WHO, tobacco consumption would annually account for 8 million cases of mortality worldwide [5].

A review article which explored 129 published works of research in 68 countries showed that the majority of the studies reviewed showed an increasing rate of HS between 2009 and 2016. This increase has shown to be annually between 0.4 and $2.9 \%$ in east Mediterranean area and between 0.3 and $1 \%$ in Europe [6].

Iran is among countries with a high prevalence of HS. The prevalence rate of HS in Iran is close to the global rating due to the wide availability of hookah, its various tastes and low cost. Hormozgan, a province in the south of Iran, hosts many hookah smokers, which is due to specific culture, underestimation of the hazards of hookah, job opportunities related to hookahs and failure to control and manage this tobacco product [7]. Some research showed that the prevalence of HS was $28.4 \%$ and $45.2 \%$ among men and women, respectively[8] 
As a complicated behavior, HS is influenced by many internal and external factors. Some are individual, while others are inter-individual, social, political and organizational. Among these factors are positive attitude, underestimation of the hazards of HS, psychological and social gaps, physical and mental attachment to hookahs, family-related factors, media advertisement, ease of access (availability) and the absence of probative rules and poor monitoring and management $[7,9,10]$. In some other research, family support, social and psychological needs, family norms, control of external stimuli and political factors were among effective factors in hookah cessation[11]. In their study in the east Mediterranean region, Afifi et al. showed that socio-cultural norms, sensory characteristics of HS, motivation to smoke, gender differences, comparative effects of hookah and cigarette smoking and indicators of dependence/consumerism metaphors were among the determinants of HS[12] .

Although controlling the effective factors in HS or cessation behavior can, to some extent, help prevent this unhealthy behavior, discovering the determinants of controlling HS can be particularly useful in this regard.

The related literature has been more focused on controlling cigarette smoking (among all tobacco products). These studies have not attended to all aspects of preventing and controlling cigarette smoking and each has addressed one aspect [13-15] .

Seemingly, researchers have neglected the exploration of Determinants Controlling HS, According to our knowledge, as no qualitative or quantitative research has been conducted to explore the topic. Thus, it is essential to fill the existing gap in the literature. as well as the comments made by experts in this area can be illuminating with this respect. To the best of our knowledge this research is actually the first study aiming to explore the Determinants control of HS.

\section{Method And Materials}

\section{Study design}

The present research is a qualitative study conducted as face-to-face interviews locally. The interviews were in-depth semi-structured in type and were held between 2018 and 2019 in Bandar Abbas, a city in the south of Iran. Moreover, to further explore the Determinants, experts in HS control also participated in in-depth semi-structured interviews.

\section{Participants and recruitment}

The women participating in this research were those with an experience of daily HS for at least 6 months, those having successfully ceased smoking before they smoked constantly on a daily basis. The high prevalence of HS among women and their close attachment and positive attitude to HS (compared to men) were among the reasons why we selected women hookah smokers as the target research population[16, 17]. (17-19). Besides women hookah smokers, experts with at least 5 years of work 
experience in controlling and preventing tobacco consumption and the least academic degree of B.S. entered the study.

Inclusion criteria for women participants: those with a history of failed cessation and smoking at the time of study, those with a history of successful cessation, all capable of information sharing, and native to Bandar Abbas. Inclusion criteria for experts: the most knowledgeable in the topic of interest. Exclusion criterion: unwillingness to participate in the research

To conduct the interviews, a primary version of the interview guide was developed in two sections, the first comprised of personal information such as age, place of residence and state of cessation, and the second concerned with participants' overt and covert beliefs about the topic of interest. The validity of the interview guide was checked by a panel of 5 experts in Smoking control and qualitative research methodology After the first five interviews, according to the participants' feedback, the interview guide was adapted and finalized. The final version was used as the basis of all the remaining interviews. Each interview was initiated with 4 main questions in the interview guide. As the interview went on, follow-up questions were asked to further delve into the details and probe questions were asked to go deeper into the topic of research. The main questions in the interview were: In your opinion, what strategies can help people to cease HS? What others should do to help people cease HS? What do you suggest we can do to control HS in this city ,What the government, NGOs, etc. should do to help people cease HS??

\section{Data collection}

All participants consented to take part in the research in advance. They were also ensured of the confidentiality of the information they provided. The interviews were held by two researchers (SD and TA) and took about an hour. To collect the required data, firstly, 8 different regions were selected in Bandar Abbas (in the north, south, west, east and center), which had the most prevalence of HS. Having notified the local council in each region, the first experienced women in the target topic was selected and was visited by the researchers. The purpose of research was introduced and a written letter of consent was obtained from the woman to audio-record the interview. The time and place of the interview was as preferred by the participating woman. All the interviews were held in a quiet place such as the interviewee's home or a mosque or anywhere else preferred by the participant. After each interview, the interviewee was asked to suggest the next potential participant with the experience of HS. Thus, the sampling was purposive and snow-ball in type. Sampling the panel of experts was also purposive and snow-ball in type. Initially, the anti-tobacco consumption organization in Hormozgan province was visited to get access to the first expert in the topic of concern. After setting an appointment with the first expert, the time and place of the interview was set as the interviewee preferred. After the interview, the expert was asked to suggest the next expert. The data collection continued until data satiation.

\section{Rigor}

The following attempts were made to add to the rigor of the findings: 1 . Sufficient time was spent on data collection (August 2018-June 2019); 2. To make sure of the accuracy of researchers' interpretation of participants' comments, the findings were availed to some of them. After receiving feedback, minor 
changes were made to the data; 3 . The data were provided to two colleagues (AH, $M G)$ who were experts in qualitative research approach. Their comments helped to define and revise the categories and subcategories. To ensure the confidentiality of findings, the categories, sub-categories and a sample coding were provided to two external experts (YR and SHS). Comments made by these experts and the present researchers were in some cases contradictory. It was attempted to settle these contradictions with reference to the initial interviews.

\section{Data analysis}

All interviews were recorded by SD and then transcribed on paper. After a detailed and initial analysis of the text of each interview, the next interview was planned. The interviews were reviewed independently by SD and TA line-by-line with an open coding approach to identify the concepts hidden in the statements of the participants. With the advancement of the analysis and the repeated study of the extracted codes and classes, their similarities and differences were distinguished and they were separated from each other in terms of characteristics and dimensions. Finally, by constant comparison of the classes, some subcategories were merged and the main categories were finally formed. SD and TA reviewed all the extracted codes during a meetings and discussed the categories and subcategories. They had agreement on the majority of categories and subcategories, and only had controversial views on few cases, which by referring to the initial interviews and re-examining the codes they managed to resolve. The extracted codes were processed through MAXQDA software version 10.

\section{Results}

Among the 52 women who had been initially invited to participate in the research, 41 agreed to take part. Their age ranged between 15 and 67 years (Mean $\pm S D=39.2 \pm 15.9$ ); 20 women (48.8\%) had successfully ceased HS; 21 women (51.2\%) had failed to cease HS; the history of HS ranged between 6 months and 46 years. The rate of HS ranged between 1 and 20 times a day (mean $=4.2 \%$ ) and between 7 and 200 times a week $($ mean $=20 \%$ ). Table 1 demonstrates other relevant information. 
Table 1

Demographic characteristics among women $(n=41)$

\begin{tabular}{|c|c|c|}
\hline & Categories & Number (Percentage ) \\
\hline \multirow[t]{4}{*}{ Age(years ) } & $<20$ & $4(9.8)$ \\
\hline & $20-35$ & $17(41.5)$ \\
\hline & $35-50$ & $7(17.1)$ \\
\hline & $>50$ & $13(31.7)$ \\
\hline \multirow[t]{5}{*}{ Educational level } & illiterate & $8(19.5)$ \\
\hline & primary & $6(14.6)$ \\
\hline & secondary & $5(12.2)$ \\
\hline & diploma & $11(26.8)$ \\
\hline & college & $11(26.8)$ \\
\hline \multirow[t]{2}{*}{ Marital status } & Single & $9(22)$ \\
\hline & Ever married & $32(78)$ \\
\hline \multirow[t]{2}{*}{ Professional activity } & Not working & $31(75.6)$ \\
\hline & Working outside home & $10(24.4)$ \\
\hline \multirow[t]{3}{*}{ Age at the start of smoking (years) } & $10-15$ & $9(22)$ \\
\hline & $15-20$ & $11(26.8)$ \\
\hline & $>20$ & $21(51.2)$ \\
\hline \multirow[t]{3}{*}{ Smoking per day } & $1-2$ & 13(31.7) \\
\hline & $2-4$ & $17(41.5)$ \\
\hline & $>4$ & $11(26.8)$ \\
\hline \multirow[t]{5}{*}{ Residence } & North & $7(17.1)$ \\
\hline & South & $8(19.5)$ \\
\hline & West & $9(22)$ \\
\hline & East & $9(22)$ \\
\hline & Center & $8(19.5)$ \\
\hline
\end{tabular}

Among the 22 experts in tobacco consumption, 21 experts entered the study. One expert refused to participate due to work obsessions. The expert interviewees' work experience ranged between 5 and 28 
years $($ mean $=20)$. Table 2 demonstrates other relevant information.

Table 2

Demographic characteristics among Expert $(n=21)$

\begin{tabular}{|lll|}
\hline \multirow{2}{*}{ Age( years ) } & \multicolumn{1}{l}{ Categories } & Number (Percentage ) \\
& $30-40$ & $5(23.8)$ \\
\cline { 2 - 3 } & $\mathbf{4 0 - 5 0}$ & $12(57.1)$ \\
\cline { 2 - 3 } & $>50$ & $4(19.1)$ \\
\hline Educational level & bachelor's degree & $6(28.6)$ \\
\cline { 2 - 3 } & master's degree & $7(33.3)$ \\
\cline { 2 - 3 } & PhD & $8(38.1)$ \\
\hline Marital status & Single & $4(19)$ \\
\cline { 2 - 3 } & Ever married & $17(81)$ \\
\hline work experience & $5-15$ & $4(19)$ \\
\hline & $15-25$ & $14(66.7)$ \\
\hline & $>25$ & $3(14.3)$ \\
\hline
\end{tabular}

The data analysis led to the extraction of 5 main categories and 21 sub-categories (Table 3). 
Table 3

Determinants of HS control

\begin{tabular}{|c|c|}
\hline Categories & Sub-categories \\
\hline \multirow{6}{*}{$\begin{array}{l}\text { Employing influential characters to } \\
\text { address HS }\end{array}$} & NGOs Participation \\
\hline & Family support \\
\hline & Mass Media and social networks' activities \\
\hline & Peer education \\
\hline & well known figures and Celebrities advocacy \\
\hline & Innovative and creative entrepreneurship for salespeople \\
\hline \multirow[t]{2}{*}{ Controlling HS by alternative services } & Setting up recreational facilities \\
\hline & Holding festivals and Joyful activities \\
\hline \multirow{4}{*}{$\begin{array}{l}\text { Changing beliefs and attitudes toward } \\
\text { HS }\end{array}$} & Prohibiting any firm of HS advertising \\
\hline & $\begin{array}{l}\text { Showing HS as an abnormal behavior (in people with low } \\
\text { self-esteem) }\end{array}$ \\
\hline & Public education regarding HS consequences \\
\hline & Use of religious beliefs against HS \\
\hline \multirow{6}{*}{$\begin{array}{l}\text { Executing administrative and regulatory } \\
\text { measures }\end{array}$} & Anti-HS legislating and enforcing regulations \\
\hline & participatory administration \\
\hline & Deciding on tax policies \\
\hline & Promoting citizens' rights \\
\hline & Segregation of HS places \\
\hline & Setting limits \\
\hline \multirow[t]{3}{*}{ Facilitating HS cessation } & Establishing HS cessation clinics \\
\hline & motivational services \\
\hline & Providing mental health consultations \\
\hline
\end{tabular}

Category 1: Employing influential characters to address HS

Employing influential characters showed to be a key Determinant in the control of HS. This main category had several distinct sub-categories which are addressed here.

\subsection{NGOs Participation}


As the majority of participants believed, NGOs, if employed effectively besides executive governmental organizations, can bring many innovative ideas and potentials and can significantly help to prevent, control and cease HS. More public reliance on and better reception of NGOs can be one reason why NGOs should be essentially involved in making the required preventive measures by the government. Here are some participants' comments with this respect

"Attempts at incorporating NGOs can have dramatic effects, as NGOs are created by people themselves. That is why the public trust them more, because they are seen as the link between people and the government. NGOs communicate well with ordinary people". (Interviewee No. 18)

"NGOs have great potentials to help. If the government grants them a budget, they can manage it well. If they find themselves with a well-defined route, people welcome them more and cooperate with them more". (Interviewee No. 50)

\subsection{Family support}

According to the participants, family support and supervision can be a strong barrier to such damaging behaviors. Inadequate support would lead to deviation and improper decisions including one's tendency toward HS". Some relevant extracts from the interviews are:

"All factors affecting HS can be summarized in the term family support. If one is both psychologically and spiritually supported by the family, s/he would hardly ever tend to smoke hookahs". (Interviewee No. 43)

"Nowadays, families have almost no control over children. They are left to their own devices. Family members live in the same house but each on his/her own. Such family neglect can pave the way for such unhealthy behaviors". (Interviewee No. 49)

\subsection{Mass Media and social networks' activities}

As maintained by the majority of participants, forbidding any form of advertisement, direct or indirect, for hookahs in mass media can be an effective back-up strategy to control and prevent SHSHS. Introducing HS extensively as an abnormal behavior in mass media can tremendously influence public belief and attitude. That is due to the trust people put in mass media. Here are some extracts from the interviews:

"Mass media has been successful in annihilating certain unhealthy behaviors such as crack consumption. They highlighted the adverse effects and managed to create a deep fear of this drug among the public. Finally, the drug abuse was under control. HS can be also controlled in a similar way".

\section{(Interviewee No. 28)}

"The TV series shown regularly should advertise against tobacco. At least they can avoid publicizing tobacco. So, they can be really effective. In some series, the main characters smoke cigarettes or hookahs in front of the camera". (Interviewee No. 44) 
"Cartoons and photos can be used to show those smoking hookahs are of low self-confidence. They lack respect for themselves. Hookahs should be depicted smoked by negative characters or those of indecent appearance so as to affect public belief". (Interviewee No. 53)

\subsection{Peer education}

Peer instruction was perceived by many participants as an effective strategy to control HS. Here is a relevant comment:

"I think if instructions are provided by peers, they are more effective because those emotions, attitudes and norms are better expressed and teenagers listen more to their peers and they communicate much better". (Interviewee No. 53)

\subsection{Well-known figures and Celebrities advocacy}

As pinpointed by man participants, the information provided or the kind of advice given by reliable sources can significantly affect HSs' belief and attitude. These reliable sources can include family members, celebrities or popular football players among youngsters as well as clergymen who can talk against HS and help to change behavior. A relevant extract follows here:

"It has been 10 years since I quit. A neighboring woman, with whom I made friends, talked about the damage it could cause to lungs and heart. As I trusted her, I believed what she said. She has always been there for me. Whatever she says, I tend to believe. Two of her sons are doctors". (Interviewee No. 10) Another participant commented:

"If a celebrity does the favor and advertises against HS, that will be excellent. Many followers will never want to smoke hookahs or if they are already users, they quit" (Interviewee No. 7).

\section{Category 2: Controlling HS by alternative services}

As the majority of participants reckoned, appropriate alternative services can act as an effective strategy to control of HS. As commented by the interviewees, hookah can only be discarded if it is replaced by a better choice. There are several sub-categories here supported with some comments made by the participants:

\subsection{Innovative and creative entrepreneurship for salespeople}

As the majority of participants believed, it is essential to find a job for those who earn a living by selling hookahs. If they job is not replaced by a better job, they will never cease selling hookahs, and this will have many socially adverse effects.

Here is a relevant account from an interview 
"The government is supposed to use the least budget available to provide hookah sellers an appropriate job. For instance, the government can help them with interest-free loans. Or it can build a market where all these ex-hookah-sellers work and can earn a living" (Interviewee No. 50).

\subsection{Setting up recreational facilities}

As the majority of participants maintained, extending recreational activities can significantly help to control and reduce the rate of damaging behaviors such as HS. Unfortunately, Bandar Abbas is less equipped with recreational facilities than other cities. Thus, there is not a wide range of leisure time activities to choose from. With this respect, the following comments were made:

"The more recreational facilities are provided for families, the less the probability of HS. Yet, these are largely absent here. Unfortunately, there is not a single reliable park or green space here.". (Interviewee No. 37)

Moreover, reconstructing and renovating old urban space which can house damaging behaviors (such as parks, gyms, pedestrian walks, biking lanes) can be a key supportive strategy to prevent, control and cease HS. As raised by many participants, there is no space for sports and physical activities in their neighborhood. A relevant account follows:

"There is not even an empty land in our neighborhoods where children can go and play for example football when they feel free. Neither is any space for women to walk. When there is no hobby, they have no choice other than amusing themselves with HS". (Interviewee No. 5)

\subsection{Holding festivals and Joyful activities}

As suggested by most participants, activating and employing all existing sources can effectively help to prevent, control and cease HS. For instance, investing on the young talents in art, music, theater and the like, employing them in joyous celebrations in neighborhoods and moving celebrations and festivals out of official, indoor space to outdoor space and more specifically to neighborhoods which can otherwise become a center for HS, and establishing the anti-hookah culture in such celebrations can be promising endeavors.

"I think, if regularly and for any possible reason, amusing programs were planned to be run in neighborhoods, people would choose to participate in such programs or get-togethers instead of smoking hookahs. Such celebrations can provide a good chance for reminding people of the adverse effects of HS". (Interviewee No. 48)

"Bandar Abbas is a town of music! Many youngsters show interest in music and try to become famous one day in this area. If they are provided with the right facilities, they can even perform unpaid! They have shown other talents too, such as theater, poetry and so on. If the way is paved for their public presence and performance in a safe and secure environment, they can readily and happily take part". (Interviewee No. 55) 


\section{Category 3: Changing beliefs and attitudes toward HS}

Changing people's beliefs and attitudes was another category mentioned by the participants among factors affecting controlling HS. This category had several sub-categories as described below along with some quotations from interviews.

\subsection{Prohibiting any form of HS advertising}

As most participants believed, prohibiting any form of advertising HS can be effective in preventing adolescents' and youngsters' addiction. These advertisements create a positive attitude in the audience about the tobacco product and they also encourage people to smoke tobacco products. Here is a relevant comment:

"Exposing hookah products at the entrance of shops is a kind of advertisement. If we truly wish to control HS, we should prevent any form of advertisement for HS in shops and within the city and also in TV". (Interviewee No. 53)

\subsection{Showing HS as an abnormal behavior (in people with low self-esteem)}

As the majority of participants believed, creating an unpleasant and socially unacceptable image of HS can be a great help to changing people's attitude.

Here is a relevant account

"HS, similar to crack and shisha, should be condemned. We need more advertisement against the hazards of HS in community. Hookahs should be illustrated as used by frauds. This can show a negative image of the behavior. The same was done for crack and it soon was condemned at a social level. The same can go for hookahs".

\subsection{Public education regarding HS consequences}

The majority of participants were aware of the key role of continuous and purposeful education with the aim of highlighting the adverse effects of HS everywhere especially where hookah is served and changing public attitude. As an instance, depicting horrifying images of the adverse effects of consumption, interview with smokers who have shown the adverse effects, interview with those with a history of failed or successful cessation, the physical benefits of cessation and constant reminding of the detriments of HS are among the effective strategies. Some are depicted in the following extract:

"To change public beliefs, education should be continuous and influential. Now, there is a lack of education on HS, or the scarce educational attempts have been short-term and temporary. They will stop and delayed to long time later". (Interviewee No. 50)

Many participants maintained that education on the prevention, control and cessation of HS needs to be implemented. It should be attractive and high-quality too in order to cause a behavior change. Experts' 
comments should be followed with this concern. (Interviewee No. 14)

"The kind of instructions provided by experts with this respect have not be potent or influential, as the experts themselves have not been trained practically in this area. Such poor educational attempts would fail to have any significant effect to motivate cessation. Often, experts are not able to give logical answers to consumers' questions". (Interviewee No. 42)

\subsection{Use of religious beliefs against HS}

As raised by a number of participants, religious beliefs and emphasis on it can be a great support to the prevention, control and cessation of HS. Here is a comment made by a participant:

"I was always wondering why we don't link tobacco consumption with certain verses from Kuran. This can really help if we raise holy narrations that directly address the issue that causing any damage to body is Haram (forbidden). These narrations can be linked with hookahs. We can claim that as HS damages health, it is deemed Haram. The faithful in Islam would care about this". (Interviewee No. 8)

"If there is more and more spiritual support in society, there can be more peace too. More peace is followed by less stress and people would naturally try smoking hookahs". (Interviewee No. 19)

\section{Category 4: Executing administrative and regulatory measures}

Another frequent theme was subsumed under the development of new rules and regulations, and was stated by the majority of participants as an essential strategy. As suggested, these new rules should be preventive, controlling and inhibiting. As the interviewees admitted, there is currently no law against HS. If there is any, it is hardly implemented. There are several sub-categories too as summarized below

\subsection{Anti-HS legislating and enforcing regulations}

As put forth by many participants, giving heavy fines for HS can to a great extent succeed in reducing the rate of this unhealthy behavior. Part of an interview reads:

"Though many restaurants and coffee-shops are not permitted to sell hookahs, they break the rules and provide HS services. Even only one day after they are fined, they get back to the same track. It is because there has been no severe legal prosecution. A minor fine does nothing to stop a high-income restaurant or coffee-shop owner selling hookahs". (Interviewee No. 28)

\subsection{Participatory administration}

As recurrently stated by several participants, intersectional cooperation of authoritative organizations can dramatically affect the prevention, control and cessation of HS. Here is a comment with this respect:

"All those in charge of part of the program should gather around and start working in harmony. They are to support each other and each should take charge of a specific task. Now, it is not so, as each 
organization is working independently and not as a teamwork. There is no follow-up. One or two organizations alone cannot do the whole thing". (Interviewee No. 34)

\subsection{Decide on tax policies}

As suggested by many participants, putting higher taxes on hookah service providers such as coffeeshops or else can effectively prevent and control HS in society. They suggested that hookah selling shops should be divided in two types, smoking and non-smoking. Coffee-shops or restaurants that are of the smoking type should pay higher taxes (3 or 4 fold). Here is a relevant extract:

"In many European countries, there are higher taxes on cigarettes and tobacco products. The same should go here. Coffee-shops that offer hookah services should pay taxes three times as high as others" (Interviewee No. 53)

Another account reads

“Municipal taxes should be 3-4 folds for coffee-shops that sell hookahs. They should pay taxes this year as they endanger citizens' health. The next year, it's their choice whether they will continue selling hookahs or not". (Interviewee No. 49)

\subsection{Promoting citizens' right}

Most of the participants agreed that making the society aware of the citizen rights can to a great extent change public view of HSs. Air pollution follows from HS and when the public feel that they have been deprived of their right to access clean air, they begin to protest to those contaminating the air in selfdefense. A relevant comment is presented here:

"I think awareness of citizen right can be truly effective. We should change the public view. If a family passes by me and looks down on me, that would be the end of me. No need to talk! Their silence would mean that this is our right to enjoy clean air. For sure, that would be effective". (Interviewee No. 40)

\subsection{Segregation of HS places}

segregation of specific places for HS was another strategy suggested by many participants to prevent, control and cease HS. This category actually points to the necessity of making strict laws to take away hookahs from public places and confine it to enclosed spaces spread apart from each other.

"If anyone who used to freely smoke hookahs at the beach or in parks now is forced to go to an enclosed area for smoking and knows that s/he cannot smoke hookahs in public anymore, s/he might lose interest in smoking hookahs".

\section{6 -Setting limits}


Concentrating all hookah selling centers in one place, forbidding the sale of hookahs to those below 18 years of age, forbidding the sale of hookahs for 10 consecutive nig HS, keeping a distance of at least 100 meters from schools, setting certain limits such as no serving of food or drink besides hookahs, reducing the attractions and facilities of hookah selling places, no music play, no trees or plants around the area were all among the limits suggested by the participants to control and prevent HS. Others include going strict on giving the required work permissions to applicants can help to control this unhealthy behavior. Each of the above-mentioned strategies was supported with participants' comments:

"Shops that serve hookahs should be at least 100 meters away from schools. Otherwise, they can be tempting for schoolers especially high school students who might want to try different flavors as they find the shop nearby". (Interviewee No. 53)

"In one city, only a limited number of shops should be permitted to sell hookahs. Hookahs should not be served in every neighborhood, street or near schools. This can significantly limit access". (Interviewee No. 43)

"A child below 18 years of age may neglect health. That is because of the teenage during which people like to show off and that can move them towards such unhealthy behaviors. We need law to prohibit selling hookahs to those under 18". (Interviewee No. 17)

"Certain limits should be set. For example one who smokes hookahs should not be allowed to do so in parks or greeneries. Then, gradually, we can add to it and say for example that HSs are not allowed to watch TV or something like that. No side dish should be allowed to serve with hookahs. This can tremendously cut down on the original attraction". (Interviewee No. 30)

"If only there were stricter rules for permitting work trades, this problem could be tackled much easier. Even small local shops that sell hookahs at the beach are not authorized to do so. They should be obliged to get the required permission. This way, not every little shop can easily sell hookahs". (Interviewee No. 51)

\section{Category 5: Facilitating HS cessation}

Facilitating hookah cessation was another strategy that was suggested to control this tobacco product. This will be explained below along with some extracts from interview content.

\subsection{Establishing HS cessation clinics}

Attempts to establish tobacco cessation centers was mentioned as another back-up service to prevent, control and cease HS. The majority of smokers, when tired of the habit, look for places that can help them to cease HS. Here are some relevant accounts:

"If there are certain clinics established only to help people to cease HS, they can really help! People need to be notified at once and be encouraged to visit such clinics. These clinics should be staffed with 
supportive experts that can attract people and teach them what to do in an interesting manner". ". (Interviewee No. 4)

"There exists no such a thing as an independent tobacco cessation clinic in our city! If such clinics are established and are staffed with psychologists, physical educationalists and physicians and if people are informed of such a place, those tired of smoking can take shelter". (Interviewee No. 10)

\subsection{Motivational services}

The majority of participants mentioned encouraging and motivating individuals or a mixture of motivational strategies as an effective supportive strategy in the control of HS. Providing certain services such as travel ticket discount, concert ticket discount and gift cards to those succeeding in cessation can motivate them to continue the healthy behavior and encourage others to cease smoking too. With this concern, here is a participant's account:

"We spent a lot of money annually on medical treatments. If a third of this amount is spent on encouraging and motivating people to stop smoking hookahs, that would be much more beneficial. The act of encouragement really matters. In fact, with the least amount of money, we can control the damage". (Interviewee No. 60)

Allocating a budget to healthy entertainments such as cinema, concert, library and musical work can be another effective strategy in control of HS. In other words, people can be provided with cultural activities at a low cost.

"If there is cultural subsidy for healthy reactions, for example, if they (the government) pay part of the cost for concerts, cinemas and gyms, everyone can enjoy healthy leisure at a low cost. The reason why almost everyone smokes hookahs is that it is a cheap amusement". (Interviewee No. 42)

Also, The participants believed that hookahs could not be taken away from consumers or salespeople unless they were replaced by appropriate alternatives. With this regard, an extract reads:

"No force is going to work! There should be some rewards. When something is taken away from someone, something should be given in place. If you only think of HS as a hobby, you should begin to think what other hobbies can replace it. Even the salespeople should be provided with an alternative job". (Interviewee No. 20).

\subsection{Providing mental health consultations}

Many participants mentioned mental health consultations as a key Facilitating HS cessation involved in the control of HS. Such supportive acts can include stress management through regular periodic screenings for mental health, active education on life skills from early childhood that can help people to learn to react appropriately to stress, anger, temptation and learn to reject indecent suggestions made by 
peers. Another supportive service can be the establishment of centers aiming to provide free face-to-face or on-call psychological services around the day. Here is an extract from the interviews:

"Most people find themselves smoking hookahs to escape stress. So, if such mental problems as stress are screened for from school time and even earlier from pre-school, what can later on cause HS may be prevented". (Interviewee No. 54)

Concerning education on life skills, here are some extracts

"Education should start from early childhood. Life skills and precautions on peer pressure should be educated earlier so that they can be internalized, exactly like a football player, who learns the skills before he can learn how to implement them. We should teach the skill of resisting peer pressure and other similar temptations for HS". (Interviewee No. 46)

"Teaching life skills can be a great help as they actually include learning problem-solving, stress management, anger control and better self-care". (Interviewee No. 43)

With regard to free psychological consultations, a participant quoted:

"If families, when in trouble and stressed-out, could refer to an advisor for help and be appropriately supported, for sure they would not have to rely on HS to lessen their stress. The advisor needs to be available and ready to help either face to face or when consulted on phone. Such advisors need to be supported by the executives". (Interviewee No. 48)

\section{Discussion}

The present research is pioneering in employing a qualitative content analysis to explore the Determinants of HS control.

As the present results showed, 'Employing influential characters to address HS' was a key Determinant in the control of HS. In some other research, influential characters was found as a key factor involved in tobacco cessation procedures [18]. In the present research, influential characters included different strategies, one of which was the emergence of NGOs. It seems that NGOs that originate from people themselves are more trustworthy. Thus, if characterized by expertise, vigilance and organization, NGOs can help the government to control tobacco consumption. With this regard, another study revealed that NGOs played a major role in tobacco control measures taken around the world. They acted effectively in raising the victims' awareness and rehabilitating them by constantly supporting them to control this unhealthy behavior [19].

'Family support' as another trusted influential to stand against this health issue. it can be inferred that family support somehow reflects social support which is a key theoretical concept involved in successful cessation attempts in families [20]. Supportive or non-supportive family behaviors are truly effective in tendency to cessation [21]. A research has also drawn attention to the role of family support in cigarette 
cessation [22]. As reported in a review article, family plays a major role in the act of beginning to smoke [9]. This can be explained by the fact that when one is stressed-out, being socially supported in a warm casual environment can be a great help to remove stress and stand against problems. Therefore, one is empowered to tackle problems and manage stress. Thus, it is highly recommended to strengthen supportive family ties

'Mass media' was mentioned as another trusted influential aiming to control HS. The interviewees believed that mass media could advertise more effectively to tackle the issue at hand. People in general trust mass media more; thus, acquiring information from these reliable sources can deeply affect their belief. Regarding this, a study revealed that mass media advertisements were positively correlated with the reduced rate of tobacco consumption [23]. It is thus suggested that regular and periodic campaigns are held in mass media to control tobacco consumption. This can probably manage, at least partly, to control this unhealthy behavior. Similarly, another study showed that mass media campaigns were considered as a key strategy to reduce the rate of tobacco consumption among the youth [24].

As the present findings showed, peer instructions showed to be another useful strategy to control HS. It seems that this factor can significantly help to control the unhealthy behavior. In another research, similarly, peer instruction was mentioned as an effective method in changing tobacco smoking behavior [25].

'Information provision by Well-known figures and Celebrities' was another Determinant raised by the interviewees to eradicate the target unhealthy behavior. Regarding this, another study mentioned others' recommendation as a main factor involved in cigarette cessation [26]. It can be maintained that a factor that can encourage people to cease smoking hookahs is the act of acquiring information from reliable sources or people.

Another Determinant raised from the present findings was 'alternative services'. One such alternative service was 'innovative and creative entrepreneurship' which involved finding an appropriate job to replace hookah salespeople. It appeared that economic pressures and lack of appropriate job opportunities led people to such jobs as selling hookahs or offering hookah services. A relevant study showed that the rate of HS was higher in low to average income countries than high income countries [27]. This finding can be explained by the fact that selling hookahs has been probably considered as an employment issue. Low-income families with no better job opportunity would have no choice but to try selling hookahs as it can be handled with little initial investment

Another Determinant pinpointed was providing 'recreational facilities' to help to prevent and control HS. It seems that increasing gyms and sport facilities in old and vulnerable areas can significantly help to prevent and control tobacco consumption. With this regard, some related works of research pointed out the insufficiency of recreational facilities in Iran as an underlying reason for HS[28, 29]. Authorities are, therefore, suggested to consider recreation seriously and act effectively o renovate urban space so as to control and cease HS better than before. 
'Holding festivals and Joyful activities' was another Determinant in controlling HS. Using all the existing capacities of society can increase pleasurable activities of all members of society. To explain more, it can assumed that those who often experience a high level of happiness have fewer emotional and behavioral problems. This is due to the fact that happiness is often followed by less depression, tension and stress. Thus, such people would stand fewer chances of orienting towards HS. Concerning this, a study revealed that non-HSs achieved a higher happiness score than HSs [30]. Thus, there is a need for national policies to create appropriate opportunities for people to show happiness

Changing people's beliefs and attitudes was another determinant of controlling HS. As the participants commented, any form of advertisement for HS should be banned. With this concern, some relevant works of research showed that media played a key role in forming attitude toward tobacco consumption and the existing evidence shows that all media related to tobacco affect tobacco consumption and prevention[23, 31]. Contrary to the present findings, another study found no significant effect of TV advertisements on non-smokers' attitude and knowledge (those who watched the advertisement versus those who did not)[32]. These divergent findings can be partly due to different purposes of research, types of tobacco product, type of advertisement and demographic features of the target populations. However, generally, it seems that prohibiting any advertisement for HS can help control this unhealthy behavior.

Effective public instructions can be effective in raising awareness of the adverse effects of HS and changing people's attitude.

Public education regarding HS consequences' that can not only help to raise awareness but can also change attitudes and beliefs. Several studies reported a positive perception of hookahs as a reason for smoking $[9,10]$. People's belief or perception can tremendously affect their prospective behaviors. If this belief is strongly rooted in science, education or experience, it can better affect future behavior [33]. Therefore, attempts to change people's belief and highlight the high risks of HS can be helpful. 'Continuous effective education' on the adverse effects of HS is also among the effective information Changing beliefs and attitudes toward HS. Seemingly, experienced and knowledgeable experts were not involved in the educational attempts, as they did not manage to motivate smokers to cease or change their belief. With this respect, a study showed that experts who were well-trained acted more effectively than those who were not trained in cessation [34]. Holding continuous and effective workshops for experts can further motivate them to help with HS preventive and controlling measures

'Religious beliefs against HS' was mentioned as another Determinant in Changing beliefs and attitudes toward HS. Concerning this, Brown and Timberlake showed that attending religious meetings once or twice a week was followed by less tobacco consumption [35, 36]. Similarly another study indicated that spiritual support managed to overcome nicotine consumption[22]. It can be concluded that spiritual beliefs can facilitate the prevention and control of tobacco. This can be explained by the fact that the true believers feel closer to God and thus experience less depression and anxiety. When mentally pressed, they adhere to God rather than abnormal behaviors such as HS. Moreover, smokers, if more religious, make 
more attempts to cease the behavior. Raising public awareness of the detriments of hookah by clergymen in mosques and other religious ceremonies and making links between Kuranic verses and adverse effects of HS are also recommended

As suggested by the participants, to control HS effectively, there needs to be a Participatory administration. It seems that if all organizations in charge share responsibilities with this regard and act cooperatively, they can be successful in preventing and controlling this unhealthy behavior. It was shown in a work of research that to challenge tobacco control, all organizations involved should act cooperatively and interdependently [37]. As pinpointed by experiences experts, non-cooperative policies that the government makes was an effective factor involved in the control of HS. As it is evident, policymakers make no use of inferiors' points of view in their policy making to control HS. If the comments made by inferior forces or even the smokers themselves are incorporated, there are more chances of compliance with rules and plans. Thus, policy makers are strongly suggested to take the comments made by inferiors into account in their decision making. With this regard, another study introduced society cooperation as a potent means of making tobacco-related policies [38]

There is also a need for 'enforcing regulations' which can significantly help to tackle the problem. One such rule/regulation can be heavy fines. There seems to be a lack of severe prohibiting law against HS. Even if the law is existent, it is not implemented effectively to prohibit the act. Another study showed that the anti-tobacco rule is mainly implemented for cigarettes and no strict rule has been either developed or implemented for hookahs [39]. In a review of the existing rules in 62 countries, influential rules/regulations could be only traced back to US, UK, India, UAE and Pakistan [40]. As a similar research showed, fining children and teenagers for carrying any form of tobacco product had managed to reduce the rate of tobacco consumption among them to a large extent $[41,42]$.

'Increasing taxes' was another Determinant in the control of HS suggested by the participants. Increasing taxes, in a relevant work of research, managed to have a significant effect on reducing the rate of smoking cigarettes [13]. Another study indicated that increasing taxes was the easiest and most economical way to control tobacco consumption in China [43]. Probably higher taxes are followed by less demand in the market. Thus, it is expected that increasing taxes can reduce or correct the pattern of HS. With this regard, WHO reported that increasing the tax for $10 \%$ on a cigarette pack can reduce the demand for cigarettes for about $4 \%$ in high income countries and $8 \%$ in average and low income countries [44] .

'Familiarization of society with citizen rights' was another effective Determinant to control HS. Probably if people know that it is their right to enjoy clean air, when they see others (HSs) are actually depriving them of this right, they will react. This would not only affect their own belief but also that of the smoker. The latter would have to be more cautious as others can easily start to complain. Concerning this, some research revealed that a tobacco-free generation corresponds to citizen rights [45]. Another study showed that any attempt to control peripheral tobacco smoke should be focused on personal rights [46]. Therefore, this factor should not be neglected in order to control this unhealthy behavior. 
'Segregation of HS places' was raised as another Determinant for HS control. Probably if HS is confined to particular places and it is banned in public space, it can tremendously help to control HS effectively. Concerning this, some review research revealed that segregating HS places can play a key role in controlling HS [10]. Another similar study showed that developing an anti-HS rule in public places and implementing it carefully can lower the mean rate of HS for about $4-10 \%$. Thus, a great many people might cease smoking [47].

Setting certain limits on the availability and purchase of hookahs can be an innovative rule which can help to prevent, control or cease tobacco altogether. Seemingly, hookahs, among all tobacco products, are easily available to the public. In another study, the participants pinpointed the lack of a prohibitory rule against selling hookahs to those under 18 in coffee-shops [48]. Some other research drew attention to the extensive and facile access to hookahs as a main reason for the high prevalence of HS [49,50]. As reported in another study, the rate of tobacco consumption showed to be significantly lower in cities with strict rules than those without [42].

Tobacco cessation clinic (TCC) was another Determinant in the control of HS that was suggested. Concerning this, a study revealed that TCC was capable of satisfying tobacco smokers' needs and managed to stop hookah cessation. By providing effective educational interventions, these clinics can play a key role in helping smokers stop smoking cigarettes [51]. Probably they can be as effective in HS cessation too.

According to the present findings, 'motivational services' was also mentioned among effective Determinant to address the target issue. Concerning this, some research showed that the rate of successful cessation of those highly motivated to stop smoking was four times as high as those who were less motivated [52]. A relevant body of research found that financial motivators could increase the rate of tobacco cessation $[53,54]$. Thus, authorities are suggested to take motivating measures to cut down on the rate of this unhealthy behavior.

One of these motivational services was 'Provision of cultural subsidy' that could help the control of HS. As many of the interviewees agreed, if there is a subsidy for such recreational activities as cinema, gym and concert, which can lower costs for people, it can tremendously help to control HS. In their research, Roskin, Roskin and Aveyard observed that the participants mentioned the low cost of HS among group amusements as a main reason why they went for it [55]. Similarly, some other research drew attention to the lower cost of hookahs than many healthy recreational activities among women smokers[28]. If authorities set a budget as cultural subsidy to support public use of healthy recreations, effective measures can be taken to control this unhealthy behavior.

'Mental health consultations' was also mentioned as another Determinant that could significantly affect HS control attempts. According to the participants, stress management through mental health screening programs, teaching of life skills and establishment of 24-hour psychological centers that served people free of charge could to a great extent meet people's psychological and spiritual needs. With this concern, some research showed that a significant proportion of respondents raised the issue of frustration and 
psychological/spiritual problems at the outset of the unhealthy behavior of drug abuse [56]. Similarly, in another study, psychological needs and gaps were mentioned as the major reasons for HS [28]. In some other work of research, phone consultation proved effective in reducing the rate of cessation[57]. It seems that meeting psychological and spiritual needs can significantly affect preventive measures for HS.

\section{Strengths, limitations and suggestions for further research}

There were certain limitations in the present research. As in all types of qualitative research, researcher's own beliefs and perceptions could have affected the procedures from conceptualization to communication with participants and data interpretation [58]. Though in the present research, exploratory heuristics was used in data analysis which helped to directly extract the categories and themes from the data produced by participants, it was possible that the questions asked in the interview did not cover all effective factors of HS. To compensate for this, the interviews continued until data satiation. Another limitation is that the extracted data might be not generalizable to other parts of the country. Despite the above-mentioned limitations, there were several strengths too. For one thing, it was a pioneering research, which provided useful information about how to prevent, control or cease HS for authorities. For another, the expert participants were selected from among the most knowledgeable in this area, with the benefit of proving realistic information for the control of HS. Further research is required to explore these strategies in more extensive areas and from all demographic groups so that we can have access to comprehensive data about the effective strategies to prevent and cease HS.

\section{Conclusion}

Overall, these findings provide a preliminary insight into the factors involved in controlling hookah smoking. The results revealed that the key determinants of controlling hookah smoking are wide and varied. They are also multi-dimensional and include different environmental, social and political factors. Controlling hookah smoking can be only effective when all individual, inter-individual, social, political and organizational determinants are considered

\section{Abbreviations}

HS: hookah smoking

\section{Declarations}

\section{Ethics approval and consent to participate}

As for ethical considerations in this study, the procedure was approved by the Ethical committee of Research in Biomedicine Tehran University of medical sciences (IR. NIMAD.REC.1398.281). The purpose of the study was revealed to all participants and they were ensured of the confidentiality of the information they provided. All participants were required to sign an informed consent and were informed 
they could withdraw in any step of the research if they desired. For the participants below 18 years of age an informed consent was obtained from parents. We can confirm that all methods were performed in accordance with the relevant guidelines and regulations of research ethics.

\section{Consent for publication}

Not applicable.

\section{Availability of data and materials}

The datasets used and analyzed during the current study are available from the corresponding author on reasonable le request.

\section{Competing interests}

The authors declare that there is no conflict of interest in this work

\section{Funding}

This research received a grant from Nimad National Institute for medical research development No. 983514

\section{Authors' contributions}

TA conceptualized and designed the project, and obtained research funding. SD led analysis of the transcripts, and with TA developed the manuscript. AH, MG and M.MA, SH performed the critical review. SD and TA responded to the reviewers 'comments. All authors reviewed and approved the final version. SD and TA are the guarantors of the manuscript. SD is the lead author, and TA is the senior author. Other authors are listed in order of contribution

\section{Acknowledgments}

The authors would like to thank National Institute for Medical Research as their financial support. The authors would also like to express their gratitude to the participants for their sincere cooperation in this study.

\section{References}

1. Mostafa A, Mohammed HT, Hussein WM, Elhabiby M, Safwat W, Labib S, Fotouh AA, Hoek J: Would placing pictorial health warnings on waterpipe devices reduce waterpipe tobacco smoking? A qualitative exploration of Egyptian waterpipe smokers' and non-smokers' responses. Tobacco control 2019, 28(4):475-478.

2. Sepetdjian E, Abdul Halim R, Salman R, Jaroudi E, Shihadeh A, Saliba NA: Phenolic compounds in particles of mainstream waterpipe smoke. nicotine \& tobacco research 2012, 15(6):1107-1112. 
3. Radwan G, Hecht SS, Carmella SG, Loffredo CA: Tobacco-specific nitrosamine exposures in smokers and nonsmokers exposed to cigarette or waterpipe tobacco smoke. Nicotine \& Tobacco Research 2012, 15(1):130-138.

4. Maziak W, Taleb ZB, Bahelah R, Islam F, Jaber R, Auf R, Salloum RG: The global epidemiology of waterpipe smoking. Tobacco control 2015, 24(Suppl 1):i3-i12.

5. World Health Organization. Tobacco key facts. Geneva,Switzerland: World Health Organization; . June 9, 2019 [ https://www.who.int/news-room/fact-sheets/detail/tobacco.Accessed]

6. Jawad M, Charide R, Waziry R, Darzi A, Ballout RA, AkI EA: The prevalence and trends of waterpipe tobacco smoking: A systematic review. PloS one 2018, 13(2):e0192191.

7. Dadipoor S, Kok G, Aghamolaei T, Ghaffari M, Heyrani A, Ghanbarnezhad A: Explaining the determinants of hookah consumption among women in southern Iran: a qualitative study. $B M C$ public health 2019, 19(1):1-13.

8. Ghanbarnejad A, Aghamolaei T, Ghafari HR, Daryafti H: Hookah smoking and associated factors in rural region of Hormozgan, Iran. Zahedan J Res Med Sci 2010.

9. Momenabadi V, Hashemi SY, Borhaninejad VR: Factors affecting hookah smoking trend in the society: a review article. Addiction \& health 2016, 8(2):123.

10. Dadipoor S, Kok G, Aghamolaei T, Heyrani A, Ghaffari M, Ghanbarnezhad A: Factors associated with hookah smoking among women: a systematic review. Tobacco Prev Cessation 2019, 5:26.

11. Dadipoor S, Kok G, Heyrani A, Aghamolaei T, Ghaffari M, Ghanbarnezhad A: Explaining the determinants of hookah smoking cessation among southern Iranian women: a qualitative study. Journal of Substance Use 2020:1-6.

12. Afifi R, Khalil J, Fouad F, Hammal F, Jarallah Y, Farhat HA, Ayad M, Nakkash R: Social norms and attitudes linked to waterpipe use in the Eastern Mediterranean Region. Social Science \& Medicine 2013, 98:125-134.

13. Ho L-M, Schafferer C, Lee J-M, Yeh C-Y, Hsieh C-J: Raising cigarette excise tax to reduce consumption in low-and middle-income countries of the Asia-Pacific region: a simulation of the anticipated health and taxation revenues impacts. BMC public health 2018, 18(1):1187.

14. Cummings KM, Mahoney MC: Strategies for smoking cessation: what is new and what works? Expert Review of Respiratory Medicine 2008, 2(2):201-213.

15. Black III JH: Evidence base and strategies for successful smoking cessation. Journal of vascular surgery 2010, 51(6):1529-1537.

16. Eshah NF, Froelicher ES: Knowledge, attitudes, beliefs and patterns of waterpipe use among Jordanian adults who exclusively smoke waterpipes. European Journal of Cardiovascular Nursing 2018, 17(1):85-92.

17. Salameh $\mathrm{P}$, Khayat $\mathrm{G}$, Waked M: Lower prevalence of cigarette and waterpipe smoking, but a higher risk of waterpipe dependence in Lebanese adult women than in men. Women \& health 2012, 52(2):135-150. 
18. Burns RJ, Rothman AJ, Fu SS, Lindgren B, Joseph AM: The relation between social support and smoking cessation: revisiting an established measure to improve prediction. Annals of Behavioral Medicine 2014, 47(3):369-375.

19. Misra S: Department of Consumer Affairs Ministry of Consumer Affairs, Food and Public Distribution Government of India.

20. Westmaas JL, Bontemps-Jones J, Bauer JE: Social support in smoking cessation: reconciling theory and evidence. Nicotine \& tobacco research 2010, 12(7):695-707.

21. Hubbard G, Gorely T, Ozakinci G, Polson R, Forbat L: A systematic review and narrative summary of family-based smoking cessation interventions to help adults quit smoking. BMC family practice 2016, 17(1):73.

22. Echer IC, Barreto SSM: Determination and support as successful factors for smoking cessation. Revista latino-americana de enfermagem 2008, 16(3):445-451.

23. Emery S, Kim Y, Choi YK, Szczypka G, Wakefield M, Chaloupka FJ: The effects of smoking-related television advertising on smoking and intentions to quit among adults in the United States: 19992007. American journal of public health 2012, 102(4):751-757.

24. Health UDo, Services H: Preventing tobacco use among youth and young adults: a report of the Surgeon General. In.: Atlanta, GA: US Department of Health and Human Services, Centers for Disease ...; 2012.

25. Bilgiç N, Günay T: Evaluation of effectiveness of peer education on smoking behavior among high school students. Saudi medical journal 2018, 39(1):74.

26. Shamsipoor.M KBR, Mohammad Pour Asl,A, Mansouri,A: smoking status and factors influecing smoking cession among students of University of medical sciences,Tabriz,Iran. Journal of Knowledge \& Health, 6 Iranian condress of Epidemiology and public Health 2010,july 13- 15 Tuesday. Shahroud University of Medical Sciences, Shahroud, Iran, 5.

27. Stone E, Peters M: Young low and middle-income country (LMIC) smokers-implications for global tobacco control. Translational lung cancer research 2017, 6(Suppl 1):S44.

28. Baheiraei A, Sighaldeh SS, Ebadi A, Kelishadi R, Majdzadeh SR: Psycho-social needs impact on hookah smoking initiation among women: A qualitative study from Iran. International journal of preventive medicine 2015,6 .

29. Majdzadeh R, Zamani G, Kazemi H: Qualitative study of people's attitudes to smoking hookah and the ways to combat it in Hormozgan city. Hakim 2002, 5(3):183-187.

30. Ataeiasl M, Sarbakhsh P, Dadashzadeh H, Augner C, Anbarlouei M, Mohammadpoorasl A: Relationship between happiness and tobacco smoking among high school students. Epidemiology and health 2018, 40.

31. Davis RM, Gilpin EA, Loken B, Viswanath $\mathrm{K}$, Wakefield MA: The role of the media in promoting and reducing tobacco use. In.: USA; 2008.

32. Xu X, Gong T, Zhang Y, Wu C, Xie YJ, Wang HH, Zhu R, Li W, An L, Zhao Y: Evaluation of anti-smoking television advertising on tobacco control among urban community population in Chongqing, China. 
Tobacco induced diseases 2015, 13(1):1-13.

33. Glasman LR, Albarracín D: Forming attitudes that predict future behavior: A meta-analysis of the attitude-behavior relation. Psychological bulletin 2006, 132(5):778.

34. Silagy C, Lancaster T, Gray S, Fowler G: Effectiveness of training health professionals to provide smoking cessation interventions: systematic review of randomised controlled trials. BMJ Quality \& Safety 1994, 3(4):193-198.

35. Brown QL, Linton SL, Harrell PT, Mancha BE, Alexandre PK, Chen K-F, Eaton WW: The influence of religious attendance on smoking. Substance use \& misuse 2014, 49(11):1392-1399.

36. Timberlake DS, Rhee SH, Haberstick BC, Hopfer C, Ehringer M, Lessem JM, Smolen A, Hewitt JK: The moderating effects of religiosity on the genetic and environmental determinants of smoking initiation. Nicotine \& Tobacco Research 2006, 8(1):123-133.

37. Fowler G: Proven strategies for smoking cessation: Adopting a global approach. European Journal of Public Health 2000, 10(suppl_3):3-4.

38. Robertson C, Mamudu HM, Littleton M, Boghozian R, Owusu D, Collins C, Wang L, Veeranki SP: Using a collaborative approach to tobacco control efforts in marginalized communities. Online Journal of Public Health Informatics 2017, 9(1).

39. Morris DS, Fiala SC, Pawlak R: Peer Reviewed: Opportunities for Policy Interventions to Reduce Youth Hookah Smoking in the United States. Preventing chronic disease 2012, 9.

40. Jawad M, El Kadi L, Mugharbil S, Nakkash R: Waterpipe tobacco smoking legislation and policy enactment: a global analysis. Tobacco contro/ 2015, 24(Suppl 1):i60-i65.

41. Jason LA, Pokorny SB, Schoeny ME: Evaluating the effects of enforcements and fines on youth smoking. Critical Public Health 2003, 13(1):33-45.

42. Wakefield M, Giovino G: Teen penalties for tobacco possession, use, and purchase: evidence and issues. Tobacco Control 2003, 12(suppl 1):i6-i13.

43. Hu T-w, Mao Z, Shi J, Chen W: The role of taxation in tobacco control and its potential economic impact in China. In: Economics of Tobacco Control in China: From Policy Research to Practice. edn.: World Scientific; 2016: 149-168.

44. Organization WH: WHO European strategy for smoking cessation policy. In.: Copenhagen: WHO Regional Office for Europe; 2004.

45. van der Eijk Y, Porter G: Human rights and ethical considerations for a tobacco-free generation. Tobacco control 2015, 24(3):238-242.

46. Katz JE: Individual rights advocacy in tobacco control policies: an assessment and recommendation. Tobacco Control 2005, 14(suppl 2):ii31-ii37.

47. The W: Curbing the epidemic: governments and the economics of tobacco control. Tobacco Control 1999, 8(2):196.

48. Hammal F, Wild TC, Nykiforuk C, Abdullahi K, Mussie D, Finegan BA: Waterpipe (hookah) smoking among youth and women in Canada is new, not traditional. Nicotine \& Tobacco Research 2015, 
18(5):757-762.

49. Baheiraei A, Sighaldeh SS, Ebadi A, Kelishadi R, Majdzadeh R: Factors that contribute in the first hookah smoking trial by women: a qualitative study from Iran. Iranian journal of public health 2015 , 44(1):100.

50. Cobb C, Ward KD, Maziak W, Shihadeh AL, Eissenberg T: Waterpipe tobacco smoking: an emerging health crisis in the United States. American journal of health behavior 2010, 34(3):275-285.

51. Elizabeth H: Prevention of Tobacco Use and the Mass Media. International Journal in Management \& Social Science 2016, 4(6):54-65.

52. Levshin V, Slepchenko N: Determinants of smoking cessation and abstinence in a Russian smokingcessation center. 2017.

53. Etter J-F, Schmid F: Effects of large financial incentives for long-term smoking cessation: a randomized trial. Journal of the American College of Cardiology 2016, 68(8):777-785.

54. Sigmon SC, Patrick ME: The use of financial incentives in promoting smoking cessation. Preventive medicine 2012, 55:S24-S32.

55. Roskin J, Aveyard P: Canadian and English students' beliefs about waterpipe smoking: a qualitative study. BMC public health 2009, 9(1):10.

56. farhoudian A, sadr sadat J, mohamadi f,manokian A,jafari F et al: Knowledge and Attitude of a Group of Armenians in Tehran to Addiction and Substance Abuse. journal cognitive science 2008, 10(2):9-20.

57. Matkin W, Ordóñez-Mena JM, Hartmann-Boyce J: Telephone counselling for smoking cessation. Cochrane Database of Systematic Reviews 2019(5).

58. Kuper A, Reeves S, Levinson W: An introduction to reading and appraising qualitative research. $\mathrm{Bmj}$ 2008, 337(7666):404-407. 